\title{
ESTRANHOS À NOSSA PORTA
}

\author{
Francisco José Passos Soares ${ }^{1}$
}

O processo civilizatório tem modificado lentamente a condição tribal, nômade, até a atual de renúncia ao egoísmo, e de convivência pacífica, entre indivíduos e entre nações. Dito assim, parece que se vive em uma época em que a civilização encontrou seu ápice desenvolvimentista econômico, político e moral. No entanto, logo, ao acordar, fica-se atordoado por informações de todos os cantos do mundo, com conteúdos dramáticos, aterradores, consequentes ao litígio entre as nações, entre as pessoas de um mesmo país, nas comunidades, entre vizinhos e mesmo entre familiares. O fim de uma tragédia é logo substituído por outras, por vezes, ainda mais dramáticas. Quem decretou o fim da história arrepende-se, nesse momento, do apressurado prognóstico. O processo civilizatório não se resume nem se interrompe com um discurso político ou acadêmico. A história ultrapassa os seres humanos e os impõe desafios à maneira de Sísifo, condenados que estão a rolar, há milênios, as pedras da construção do edifício da solidariedade e da unidade humana, sem fronteiras políticas, econômicas, religiosas, morais.

$\mathrm{Na}$ era do simulacro, tudo soa fake, exceto a dor humana por quem a experimenta. As formas coletivas e contemporâneas de experiência da dor são exploradas na mídia diariamente até o limite da banalização do mal. Diariamente, se é animado pela mídia a assistir ao espetáculo das distintas formas de exploração da condição humana, no limite da desumanidade, da globalização sentimental da vulnerabilidade humana, até à exaustão das emoções e à indiferença diante da dor do outro. A "fadiga da tragédia" necessita da exploração cotidiana dos sentimentos mais familiares da convivência com o próximo e com o estranho familiar e da nutrição dos medos, angústias e fragilidades dos laços construídos com a família, a comunidade e a nação para criar o "pânico moral" e manter a todos como

\footnotetext{
${ }^{1}$ Professor Titular da Faculdade de Medicina da UFAL. Maceió (AL), Brasil.
}

Rev. Port. Saúde e Sociedade. 2019;4(1): 1076 - 1081. 
escravos de uma audiência que induz à solidariedade passiva ou, ao seu contrário, à indiferença ativa.

Assim, com esses dois conceitos, "fadiga da tragédia aos refugiados" e "pânico moral", e uma crítica contundente à manipulação sentimental midiática dos cidadãos comuns, Zigmunt Bauman apresenta uma teorização sociológica sobre o estranhamento e a indiferença diante da dor do outro, "estranhos que batem à nossa porta" na condição de refugiados.

Para o autor, a migração em massa não é um fenômeno contemporâneo, sendo acentuado e relacionado ao estilo de vida na modernidade com a produção de pessoas localmente redundantes ou sem valor, não empregáveis, ou de pessoas localmente intoleráveis e rejeitáveis. A oficina do diabo, capaz de gerar pessoas inúteis e descartáveis, sem remorso ou qualquer atitude empática, tem, como combustíveis, a razão do progresso econômico e as lutas pelo poder. Estas assumiram a forma de guerras comerciais financiadas pelo comércio global de armas, localizadas em países asiáticos e africanos, gerando um contingente crescente de pessoas em busca de asilo na Europa, matriz de exploração colonial dos países em conflito nos séculos anteriores.

Adensados em espaços urbanos, desenvolvem-se impulsos contraditórios de mixofilia, principal atração da vida nas grandes cidades, permitindo a experiência da descoberta e da convivência na diversidade, e mixofobia, experiência assustadora e, por vezes, incontrolável de medo do desconhecido para os mais vulneráveis. Acrescida a isso, e na base de toda a rejeição e indiferença e violência aos estranhos, recém-chegada está a condição empobrecida e vulnerável. A essa combinação de medo e ódio ao pobre, a filósofa espanhola Adela Cortina denominou Aporofobia, apresentando extensa dissertação sobre o tema em livro ainda não publicado no Brasil.

Segundo Bauman, mais dois impulsos podem ajudar a entender o ressentimento e a beligerância contra imigrantes pobres: o primeiro, a consciência pessoal e comunitária de desamparo e vulnerabilidade e o reconhecimento no outro de piores condições existenciais parecem restaurar a autoestima e a dignidade perdidas e assentar as bases para o nacionalismo, a xenofobia, o racismo, e para o segundo impulso, a agitação do emergente contingente precariado local temeroso da perda de conquistas e posições sociais. São os estranhos que vêm desafiar a precariedade humana, obrigando-a a enxergar a sua

Rev. Port. Saúde e Sociedade. 2019;4(1): 1076 - 1081. 
própria vulnerabilidade diante das forças desestabilizadoras e invisíveis da globalização.

Insiste o autor que "a única forma de escapar dos atuais desconfortos e sofrimentos futuros passa por rejeitar as traiçoeiras tentações da separação", "não existe outra saída senão a solidariedade dos seres humanos", buscando-se uma "fusão de horizontes" e não a "fissão" induzida, planejada e exasperante.

No segundo capítulo, o autor explora um neologismo carregado de ambiguidades, a securitização, utilizada, pelos políticos e pela mídia, para enfrentar a insegurança existencial dependente da velada desregulamentação dos mercados de trabalho e associada à flexibilização da mão de obra e consequente geração da categoria social dos precariados. Afirma que a securitização tem a função, pelos representantes de governos débeis ou desinteressados em enfrentar os problemas essenciais à existência da população, como a empregabilidade e a proteção, de desviar a ansiedade relacionada a esses problemas para outros que rendem pontos de aprovação em pesquisas de intenção de votos, como a luta contra a ameaça terrorista, em grande monta fabricada por esses mesmos representantes. A estigmatização dos refugiados como potenciais terroristas ameaçadores do que resta aos precariados, a identidade nacional, leva à "adiaforização", com a exclusão dos mesmos da consciência do dever e da responsabilidade moral, justificando a indiferença, a ausência de compaixão e ajuda.

No terceiro capítulo, Bauman expande a teorização sobre o medo dos cidadãos comuns e a evolução dos distintos modos de administração da insegurança existencial humana pela religião e pelos políticos, apoiando-se em autores modernos e contemporâneos - Hobsbaum, Robert Reich, Bakhtin, Kafka, Ulrich Beck, Benjamin Barber, Byung Chul Han, para afirmar que, na transição da sociedade da disciplina para a atual sociedade da performance, cada um é deixado à deriva para solucionar, no plano individual, problemas socialmente produzidos. A inadequação à tarefa impossível do êxito permanente gera, como resultado, massas de indivíduos desajustados e depressivos ocupados com a autoexploração, autoexasperação e autoexaustão. "Faça você mesmo" é o mantra atual dos solitários cidadãos urbanos, assustados com o espectro da rejeição, proscrição e exclusão. Por outro lado, a erosão da soberania territorial, decorrente da globalização do poder, distancia os indivíduos ainda mais das fontes políticas do "medo oficial". Citando Barber, o autor assume que a segurança anteriormente

Rev. Port. Saúde e Sociedade. 2019;4(1): 1076 - 1081. 
oferecida pelo Estado-nação, com homogeneidade étnica, linguística, independência e autonomia, dificulta, hoje, as aspirações humanitárias mais amplas como a interdependência, a cooperação e a edificação de bens comuns. Faltam ainda a consciência cosmopolita e as instituições políticas concretizadoras desse anseio, suficientes para o desarme das armadilhas das promessas nacionalistas sedutoras dos tiranos e tiranas.

No capítulo 4, o tema da migração humana é retomado para afirmar que, desde o início da história da Humanidade, todos são originários de um mesmo pequeno grupo da África e grandes deslocamentos e dispersão eram parte do modo de vida. Para Bauman, a crise migratória atual não oferece um padrão inédito de deslocamentos senão nas respostas políticas/sociais a eles. No entanto, se até agora todos são incapazes de estabelecer princípios e regras de convivência universal para a adoção da solidariedade e cooperação mútuas, precisa-se considerar o que Kant preconizou há mais de duzentos anos como a substituição da hostilidade pela hospitalidade, visando ao fim das guerras e à paz universal. Novos valores, direitos e deveres, em um tempo que, segundo Hannah Arendt, nega a moral em si, mas, segundo Bauman, a moral é uma propriedade cobiçada e reivindicada por todos para negar a indiferença e conferir autoridade, vantagens e superioridade em relação a competidores e adversários. A dissonância cognitiva, induzida por parte da mídia e por políticos, usa, como estratagemas, a depreciação, calúnias e acusações que desumanizam os migrantes, reduzindo ou eliminando a possibilidade de compaixão e compreensão do sofrimento alheio e permitindo todo tipo de ato discriminatório e até a violência física.

O capitulo 5 é dedicado à crítica às políticas europeias de acolhimento aos refugiados, desiguais entre os países e insuficientes porque não atingem as causas do movimento migratório. Chamados de "remanescentes", os refugiados obrigaram a Europa e demais países a encarar a imagem refletida, distorcida, da desigualdade e da desumanidade, em todo o mundo. A abordagem do gerenciamento da crise migratória baseada em direitos tem sido apontada como a solução mais humanizada e necessária para a garantia dos direitos, da segurança e da dignidade dessas pessoas em situação de vulnerabilidade.

Por fim, no último capítulo, Bauman discorre sobre a desconfiança kantiana e de Hannah Arendt da suficiência do conhecimento moral para a necessária e consequente ação moral, para compreender e explicar as raízes antropológicas e temporárias do ódio. As ideias de Leon Festinger sobre a dissonância cognitiva são

Rev. Port. Saúde e Sociedade. 2019;4(1): 1076 - 1081. 
apresentadas com as múltiplas rotas de fuga a essa condição, tendo em comum o distanciamento da armadilha do autodesprezo. A negação das evidências, então, só pode ser explicada por uma fé inabalável, firme e obstinada, imune ao argumento e a qualquer evidência, impedindo que a hipocrisia e a mentira atinjam a consciência. Essa fé seria, portanto, sustentada pelo hábito de um determinado grupo, por uma maioria sustentada em números, e não no argumento, na realidade e na evidência dos fatos. Essa pretensa característica antropológica e atemporal da condição humana é posta em questão por Bauman, que aponta novas circunstâncias circunscritas pelo tempo: a atual experiência de convivência real e virtual com múltiplos e distintos padrões de comportamento para seguir no mundo real, se é controlado e sujeito à punição e à exclusão; no mundo virtual, simplifica-se a complexidade do mundo real, controla-se o final, reparam-se os defeitos, perdoam-se os fracassos, abandona-se, sem remorso, o que desagrada.

Se, no mundo real, a crise migratória bate à porta gerando medo, ... "livrarse da necessidade de defender o significado e a gravidade dos imperativos morais aparece como um alívio bem-vindo: tornar-se moralmente cego e surdo, assumir uma opção livre dos riscos associados à sua alternativa, será suficiente, obrigado".

Certa fanfarronice de candidatos e apoiadores para com o poder das mídias sociais tem demonstrado que, se a internet não é a causa, pode, de fato, alimentar a cegueira moral em qualquer sentido ideológico. No mundo dos performers virtuais, a desconfiança impera e estabelece-se a guerra de todos contra todos. Diante da iminência do fracasso e do autodesprezo, projetam-se no outro a própria vitimização, a insuficiência e a humilhação, e localiza-se e nomeia-se o culpado. $\mathrm{Na}$ atualidade, os migrantes ocupam esse lugar de culpados pelo fracasso das democracias ocidentais.

Para o enfrentamento a essa condição, Bauman aponta o caminho indicado por Gadamer, Appiah e Malpas: o do saber o que fazer com o desafio do inevitável encontro, por meio do diálogo e da compreensão mútua, sem regras prefixadas, e construir um horizonte comum, pacífico.

Comentários finais:

O mundo se vê diante do desafio de solucionar a maior crise migratória que a humanidade já enfrentou. Assiste-se, há mais de uma década, com a perplexidade passiva de telespectadores e internautas, à massiva onda migratória de africanos e asiáticos em direção à Europa. Até que a crise política e econômica

Rev. Port. Saúde e Sociedade. 2019;4(1): 1076 - 1081. 
e os desastres naturais impuseram a fome e o desespero no continente sulamericano. Então, os migrantes, estranhos, bateram à porta.

É necessário agir com urgência e prudência para que não se reproduza aqui a intolerância e o ódio manifesto por representantes políticos e adeptos na Europa e nos Estados Unidos. Para isso, precisa-se conhecer não apenas procedimentos e estratégias positivas de enfrentamento utilizadas em outros contextos, mas, também, conhecer a teoria sociológica que sustentou a construção do diálogo entre as nações e tem evitado piores resultados e perdas desnecessárias de vidas.

O importante livro de Bauman soma-se a tantos outros para teorizar possibilidades de desenvolvimento humano no caminho para a compreensão mútua e a paz.

Uma América fundada pela miscigenação de povos distintos e permanentemente refundada pela chegada de novas pessoas em busca de oportunidades não pode se furtar a olhar para a sua história e criar pontes de acolhimento aos migrantes, internos, em suas próprias nações, e externos, fronteiriços ou não.

Esse é o caminho que se deve escolher: conhecer, construir pontes, abrir portas e fronteiras, acolher e desenvolver novas soluções compartilhadas para melhorar um planeta que deve ser comum.

\section{REFERÊNCIAS}

Bauman, Z. Estranhos à nossa porta. São Paulo: Zahar; 2017.

Rev. Port. Saúde e Sociedade. 2019;4(1): 1076 - 1081. 